\title{
Fagocitose e viabilidade monocitária de pacientes com esquistossomose mansônica na forma hepatoesplênica submetidos à esplenectomia e ao auto-implante esplênico
}

\author{
Phagocytes rate and cellular viability of the monocytes in patients with \\ hepatosplenic schistosomiasis mansoni who underwent splenectomy \\ and auto-implantation of spleen tissue
}

\author{
Carlos Teixeira Brandt ${ }^{1}$, Célia Maria Machado Barbosa de Castro², \\ Stella Maria Lisboa de Lavor $^{3}$ e Francisco Machado Manhães de Castro ${ }^{4}$
}

\begin{abstract}
RESUM0
Esquistossomose mansônica persiste como problema médico-social no nordeste brasileiro. Em crianças, o tratamento cirúrgico inclui esplenectomia e auto-implante esplênico. Este procedimento reduz a septicemia pós-esplenectomia. 0 objetivo deste estudo foi analisar a taxa de fagocitose e viabilidade de fagócitos mononucleares em portadores de esquistossomose hepatoesplênica, submetidos à cirurgia, de 1991 a 2001. Dos 22 indivíduos analisados, 11 eram portadores de esquistossomose hepatoesplênica, submetidos à esplenectomia e auto-implante esplênico (Grupo estudo) e 11 eram sadios (Grupo Controle). Os grupos tinham média de idades similar e procediam da mesma zona endêmica (Timbaúba-PE). Não se evidenciou diferença na taxa de fagocitose comparando-se o grupo controle ( $36,1 \% \pm 4,9 \%)$ e o grupo estudo (33,5\% $\pm 5,7 \%), p=0,2773$. Todavia, a viabilidade dos fagócitos após estímulo com lipopolissacarídio foi maior (94\%) no grupo controle, quando comparado ao grupo estudo (65\%), $p<0,001$. Pode-se concluir que a esplenose assegura função fagocitária normal em monócitos, entretanto, os fagócitos possuem menor viabilidade frente a um estímulo nocivo e duradouro.
\end{abstract}

Palavras-chaves: Esquistossomose hepatoesplênica. Esplenectomia. Esplenose. Monócito. Fagocitose.

\begin{abstract}
Mansonic schistosomiasis remains a medical-social issue in Northeastern Brazil. In children, surgical treatment includes splenectomy and spleen autoimplantation. This procedure reduces post-splenectomy sepsis. The aim of this study was to analyze the phagocyte rate and the cellular viability of monocytes in patients with hepatosplenic schistosomiasis, who underwent splenectomy and spleen autoimplantation from 1991 to 2001. Of the 22 individuals analyzed, 11 were patients who underwent splenectomy and spleen autoimplantation (Study group) and 11 were healthy individuals from the same region (Control group). Both groups presented similar mean age. No difference was found in the phagocyte rate between the control group $(36.1 \% \pm 4.9 \%)$ and study group $(33.5 \% \pm 5.7 \%)$. However, phagocyte viability after stimulation with lipopolysaccharide was higher (94\%) in control group, when compared to the study group (65\%), $p<0.001$. It is possible to hypothesize that monocytes from the study group patients presented a reduced response to the microorganism challenge, in the face of a harmful and long-lasting stimulus.
\end{abstract}

Key-words: Hepatosplenic schistosomiasis. Splenectomy. Splenosis. Monocyte. Phagocytosis.

1. Departamento de Cirurgia da Universidade Federal de Pernambuco, Recife, PE. 2. Departamento de Medicina Tropical e Laboratório de Imunopatologia KeizoAsami da Universidade Federal de Pernambuco, Recife, PE. 3. Cirurgia Pediátrica do Hospital da Restauração da Universidade Estadual de Pernambuco, Recife, PE. 4. Faculdade de Medicina da Universidade Federal de Pernambuco, Recife, PE.

Financiamento: Conselho Nacional de Pesquisa - CNPq

Endereço para correspondência: Dra. Célia Maria Machado Barbosa de Castro. Laboratório de Imunopatologia Keizo-Asami ( LIKA) UFPE. Campus Universitário, 50670-420 Recife, PE.

Tel: 5581 2126-8486, Fax: 5581 2126-8485

e-mail: ccastro@ lika.ufpe.br

Recebido para publicação em 23/9/2005

Aceito em 10/8/2006 
A esquistossomose mansônica persiste como problema médico-social no Nordeste do Brasil. 0 emprego, em larga escala, da quimioterapia e modificações ambientais são fatores de redução das formas graves da doença. Mas, 0 estabelecimento de novos focos de transmissão mantém a parasitose em expansão nessa região $0^{212}$.

No grupo pediátrico a forma hepatoesplênica pode determinar hipertensão porta (HP), sangramento digestivo, hiperesplenismo e hipodesenvolvimento. A maioria destes pacientes é tratada clinicamente, porém alguns requerem esplenectomia, ligadura da veia gástrica esquerda, associada ao auto-implante de tecido esplênico, no omento maior?

0 baço assume importantes funções de defesa do hospedeiro. Como um filtro captura e apresenta antígenos a um grande número de células $T$ e $B$ que residem ou circulam no sistema linfóide. A complicação mais temida, em crianças, é a septicemia fulminante pós-esplenectomia (SFPE) cuja mortalidade atinge $50-75 \%$ dos pacientes ${ }^{16}$. Tal fato é atribuído à deficiência da atividade fagocítica mononuclear ${ }^{26}$.

Do ponto de vista imunológico o baço é 0 maior órgão linfóide do organismo e o principal local das respostas imunes a antígenos originados no sangue. Ele é também a maior fonte de imunoglobulina $\mathrm{G}(\mathrm{IgG})$, imunoglobulina $\mathrm{M}$ $(\mathrm{IgM})^{13}$, e 0 maior local de produção de fatores envolvidos no processo fagocítico de bactérias encapsuladas tais como: opsoninas, tuftsin ${ }^{34}$ e properdina ${ }^{26}$. Assim, a esplenectomia implica em deficiência da atividade das células monomacrofágicas, que são responsáveis pela aderência as bactérias, seguida de fagocitose e destruição das mesmas, mediada pela geração de produtos microbicidas ${ }^{1923}$.

0 auto-implante esplênico apresenta eficácia na manutenção da função imunitária esplênica nesses pacientes esquistossomóticos que requerem esplenectomia total, destacando-se a manutenção de aspectos funcionais das células mono-macrofágicas do baço original sendo responsável, portanto, por diminuir os riscos de $\mathrm{SFPE}^{7161820}$.

Vários autores reforçam 0 benefício do auto-implante esplênico na função da resposta imunológica ${ }^{6} 7162430$. No entanto, ainda são controversos os estudos sobre quais as funções específicas exercidas pelo baço original não podem ser assumidas, de forma plena, pelos fragmentos autoimplantados ${ }^{191022}$.

A esplenectomia foi considerada durante várias décadas, como uma cirurgia benigna, e 0 baço como um órgão sem função precisa. Entretanto, a observação da SFPE tem estimulado pesquisas voltadas para a função esplênica, principalmente imunológica e as conseqüências da sua retirada17 19212326 .

0 auto-implante esplênico em bolsa, no omento maior, tem sido recomendado como a forma mais aceitável de preservar a função do baço quando a esplenectomia total é inevitável ${ }^{16}{ }^{32} 33$. No Brasil, vários autores têm dado suporte científico à importância da função do auto-implante esplênico. Esses trabalhos demonstram os benefícios da função imunológica esplênica ${ }^{679232425}$.
0 presente estudo tem o propósito de avaliar os benefícios do remanescente esplênico auto-implantado no grande omento, em pacientes com esquistossomose hepatoesplênica submetidas a esplenectomia com auto-implante de tecido esplênico, através da análise de aspectos funcionais das células mono-macrofágicas como determinação da taxa de fagocitose e análise da viabilidade celular após estimulação continuada, constituindo aspectos ainda não reportados na literatura mundial atual.

\section{PACIENTES E MÉTODOS}

Desenho do estudo e seleção de pacientes. Trata-se de um estudo de campo, prospectivo analítico, tipo corte transversal, onde os voluntários foram incluídos de forma aleatória; sendo o objeto de estudo, os monócitos isolados do sangue periférico e trabalhados in vitro.

Os 22 voluntários eram provenientes da Cidade de Timbaúba, na zona da mata de Pernambuco. Foram constituídos dois grupos: Grupo 1: Grupo controle (GC) constituído por 11 adolescentes e adultos jovens, sem esquistossomose, atestado por Kato-Katz negativo e Grupo 2: auto-implante esplênico (AI) - constituído por 11 adolescentes e adultos jovens, portadores de EHE confirmada por parasitológico de fezes ( Kato-Katz positivo), identificação de fibrose de Symmers na ultra-sonografia e que foram admitidos e operados no Serviço de Cirurgia Geral da Criança, do Hospital das Clínicas, do Centro de Ciências da Saúde, da Universidade Federal de Pernambuco, no período de 1991 a 2001. Todos os pacientes deste grupo foram submetidos à esplenectomia, ligadura da veia gástrica esquerda e autoimplante de tecido esplênico no grande omento.

No grupo controle, foram 5 (45\%) indivíduos do sexo masculino e 6 (55\%) do sexo feminino. A idade variou de 14 a 23 anos, com mediana de 16.0. No grupo auto-implante, foram 4 (36\%) indivíduos do sexo masculino e 7 (64\%) do sexo feminino. Aidade variou de 14 a 23 anos, com mediana de 15,2 . Os pacientes tinham à época da cirurgia, idades variando entre 9 e 18 anos, com mediana de 12,9 anos. A confirmação do auto-implante esplênico foi feita através da cintilografia com captação do radiofármaco em 100\% dos casos. Não houve desenvolvimento de SFPE em nenhum dos pacientes operados.

Foram excluídos pacientes com diagnóstico clínico e/ou laboratorial de doença hepática, ingestão abusiva de álcool, antecedentes de hepatite ou de doença hematológica além da utilização de imunosupressores ou imunoestimulantes durante 0 período de estudo.

Obtenção de monócitos do sangue periférico. Foram coletados $10 \mathrm{~mL}$ de sangue através de punção venosa dos indivíduos de ambos os grupos e distribuídos em containers a vácuo, contendo EDTA a 15\%. 0 sangue obtido foi então diluído na proporção de 1:1 em meio de cultura, Roswell Park Memorial Institute (RPMI) 1640, estéril, a 8ㅇ C (10mL de sangue $+10 \mathrm{~mL}$ de RPMI 1640). Aos $20 \mathrm{~mL}$ da suspensão 
foram adicionados $10 \mathrm{~mL}$ de histopaque (1077-SIGMA), sendo então centrifugados por 30 minutos a $450 \mathrm{x} \mathrm{g}\left(2^{\circ}\right.$ a $\left.{ }^{\circ}=\mathrm{C}\right)$.

0 plasma foi aspirado e a camada formada pelas células mononucleares do sangue periférico foi coletada e transferida para outro tubo. Assim, neste último tubo foram adicionados 15mL RPMI 1640, e em seguida, realizou-se centrifugação por 10 minutos nas mesmas condições anteriores. 0 sobrenadante foi aspirado e desprezado. Posteriormente, duas novas lavagens do sedimento foram realizadas com RPMI 1640, centrifugando-se por $5 \mathrm{~min}$ de cada vez. 0 sobrenadante foi desprezado e 0 sedimento foi ressuspendido em $2 \mathrm{ml}$ de meio de cultura RPMI 1640 completo, contendo soro fetal bovino a $3 \%$ e antibióticos (penicilina 100U/mL e estreptomicina $100 \mathrm{mcg} / \mathrm{mL}$ ).

Ao final, realizou-se contagem das células em câmara de Neubauer colocando-se a suspensão de células e 0 corante azul tripan na concentração de 0,3\% e diluído de 1:10. A concentração celular foi então ajustada em todos os experimentos para 1 × $10^{6}$ células/mL. Após a recuperação das células, essas foram ressuspendidas em RPMI 1640 completo, contadas e distribuídas na proporção de $10^{6}$ células/mL. Para os dois ensaios os monócitos foram obtidos após o tempo de adesão das células de uma hora e terminado esse tempo, realizou-se lavagem do poço ou da lâmina de vidro com meio de cultura RPMI, para retirada das células não aderentes restando apenas monócitos.

Avaliação da taxa de fagocitose. Para se avaliar a taxa de fagocitose, foram utilizados fungos Saccharomyces sp. Os fungos foram lavados três vezes com solução salina balanceada de Hanks (HBSS). Em seguida, $10^{8}$ fungos $/ \mathrm{mL}$ foram misturados em suspensão, contendo $10^{6}$ células $/ \mathrm{mL}$ de meio RPMI 1640.

As células mononucleares e os fungos foram distribuídos em lâminas para microscopia óptica e incubadas $37^{\circ} \mathrm{C}$, em atmosfera úmida, por um período de uma hora. Após esse período, as lâminas foram lavadas com HBSS ( com retiradas das células mononucleares não aderentes), secadas a temperatura ambiente e coradas com Diff-Quick set (Baxter Dade, Dudinen, Switzerland) . Aleitura foi feita em microscópio óptico, com aumento de 1.000 vezes. A taxa de fagocitose foi obtida em percentual, através da contagem de monócitos que fagocitaram 0 fungo, em um total de 200 células.

Avaliação da viabilidade celular. Para avaliação da viabilidade celular, utilizaram-se monócitos que foram colocados em placas tipo Falcon ${ }^{\mathrm{TM}}$, com seis poços de $35 \mathrm{~mm}$ de diâmetro cada, e dispensados $2 \mathrm{~mL}$ da suspensão com $10^{6}$ células/mL em meio de cultura RPMI 1640 completo. Esperou-se 0 tempo de uma hora para adesão das células e terminado esse tempo, realizou-se lavagem do poço com meio de cultura RPMI para retirada de células não aderentes. Deixando-se por mais uma hora na incubadora a $37^{\circ} \mathrm{C}$ e $5 \%$ de $\mathrm{CO}^{2}$ para estabilização das mesmas. Em seguida, dois poços foram preparados para cada indivíduo. Um poço em que foram adicionadas células em meio de cultura RPMI, no total de $2 \times 10^{6}$ células $/ \mathrm{mL}$ (controle) e no outro poço, células em meio de cultura RPMI, $2 \times 10^{6}$ células $/ \mathrm{mL}$, sendo $1,8 \mathrm{~mL}$ de meio RPMI e 200mcL de lipopolissacarídio de Escherichia coli, 055:B5, Difco-Detroit/USA, em solução salina na concentração de $10 \mathrm{mcg} / \mathrm{mL}$, perfazendo um total de $2 \mathrm{~mL}$ por poço (monócitos tratados). Posteriormente, as células ficaram em incubadora nas mesmas condições para início do ensaio.

O MTT (3-[4,5-dimethylthiazol-2yl]-2,5-diphenyltetrazolium bromide thiazolyl blue) é 0 sal tetrazolium que, após clivagem por desidrogenases mitocondriais de células, torna-se insolúvel em água pela formação de cristais de formazan e solúveis em solventes orgânicos. Apenas as enzimas de células vivas causam esta conversão.

Em meio de cultura com células, após adição de dimetil sulfóxido (DMSO-solvente orgânico), o MTT convertido em formanzan é solubilizado e pode ser lido por espectrofotometria em função desta conversão. Esta reação pode ser expressa em percentual de células vivas de acordo com a absorvância e obtémse então, o percentual da viabilidade celular. Para isso, após completar 0 período de 18 horas, a placa de cultura de células foi retirada da estufa e 0 sobrenadante de cada poço foi desprezado. Em seguida, a monocamada de células de cada poço, foi lavada com $1 \mathrm{~mL}$ de tampão fosfato a temperatura ambiente ( $\mathrm{PBSa}$ 0,01M pH 7,02) e colocou-se na camada de células 550mcL de PBS e $55 \mathrm{mcL}$ da solução de MTT ( $5 \mathrm{mg} / \mathrm{mL}$ ) . 0 conteúdo dos poços foi homogeneizado e a placa foi envolvida com papel alumínio ( para proteger da luz) . A placa foi incubada pelo período de 4 horas em estufa nas mesmas condições e decorrido 0 tempo de 4 horas foram acrescentados 200mcLde PBSe 200mcLde DMSO (SIGMA). Em seguida, a camada de células foi raspada de cada poço da placa por um scrape. Terminada esta etapa, 0 material foi transferido para tubos Eppendorfs, envoltos em papel alumínio e agitados em vórtex para, em seguida, serem efetuadas as leituras do material de cada poço, em espectrofotômetro, utilizando-se um comprimento de onda de $570 \mathrm{~nm}$.

Os resultados foram expressos em percentuais de viabilidade dos poços controles e dos poços de células estimuladas com lipopolissacarídio de E. coli 055:B5 (LPS) .

Para verificação de diferença entre médias dos grupos, utilizou-se 0 teste $t$ de Student para amostras independentes, análise de variância (ANOVA) e 0 teste de Tukey-Kramer caso a ANOVA revelasse diferença significante. Aceitou-se p < 0,05 para rejeição da hipótese de nulidade.

0 estudo obedeceu aos princípios da declaração de Helsinque e foi aprovado pela Comissão de Ética em Pesquisa do Centro de Ciências da Saúde da UFPE. Os voluntários assinaram 0 termo de consentimento livre e esclarecido.

\section{RESULTADOS}

Taxa de fagocitose. A Figura 1 mostra que a taxa de fagocitose, expressa pela média \pm desvio padrão do percentual, não apresentou diferença ( teste tde Student, $\mathrm{p}=0.277$ ) quando foram comparadas as médias dos percentuais das taxas de fagocitose entre os $\mathrm{GC}(36,1 \pm 4,9 \%)$ e $\mathrm{AI}(33,5 \pm 5,7 \%)$. 


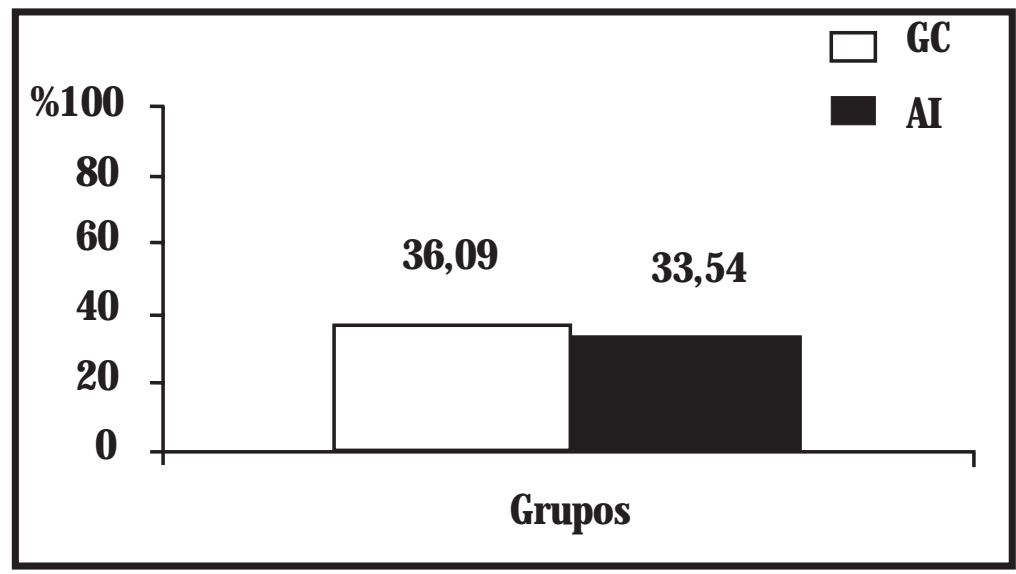

A taxa de fagocitose foi expressa pela média \pm desvio padrão do percentual. Não houve diferença entre 0 GC e AI, teste t de Student, $\mathrm{p}=0,277$.

Figura 1 - Taxa de fagocitose em monócitos.

Viabilidade celular ao 3-[4,5-dimethylthiazol-2yl]2,5-diphenyltetrazolium bromide thiazolyl blue. 0 ensaio foi subdividido em 4 grupos: 0 grupo controle, cujas células dos indivíduos não foram tratadas com LPS (GC) , 0 grupo controle cujas células foram tratadas com 0 LPS (GCLPS), o grupo dos pacientes com auto-implante e com células sem tratamento com 0 LPS (AI) e o grupo dos pacientes com auto-implante e cujas células foram tratadas com 0 LPS (AILPS). Os valores das leituras do espectrofotômetro, dados em absorvância, foram transformados em percentuais de células viáveis e representados pelas médias \pm desvios padrão do percentual de viabilidade celular.

Comparando-se dentro de um mesmo grupo, o grupo controle obteve a média de valores de absorvância de $171,8 \pm 2,9$ e $100 \%$ de viabilidade celular. Após estimulação com 0 LPS (GCLPS), a média foi de 184,4 \pm 38,4 e a viabilidade celular foi 93\%. 0 teste aplicado foi a análise de variância (ANOVA) e para situar a diferença entre as médias aplicou-se 0 teste de Tukey-Kramer para um p<0,05. Comparando-se 0 GC com 0 GCLPS não houve diferença entre os dois grupos, p>0,05 ( Figura 2).

Dentro do grupo dos auto-implantados, no AI sem tratamento com o LPS, a média foi 201,5 $\pm 33,7$ e a viabilidade celular foi $96 \%$. Após tratamento com o LPS (AILPS) foi de 234,0 $\pm 43,5$ e a viabilidade celular foi $65 \%$. Não houve diferença entre os grupos, $p>0,05$. Não havendo também diferença entre o grupo de auto-implantados com e sem LPS (Figura 2) .

No entanto, em comparações efetuadas entre os diferentes grupos (GC e AI com ou sem tratamento com 0 LPS), 0 percentual da viabilidade dos monócitos foi diferente entre os grupos GCLPS e AILPS, a diferença das médias foi igual a 49,55 e 0 p<0,05 evidenciando uma diferença significante, após estímulo por tempo prolongado com LPS sobre a viabilidade celular ( Figura 2).

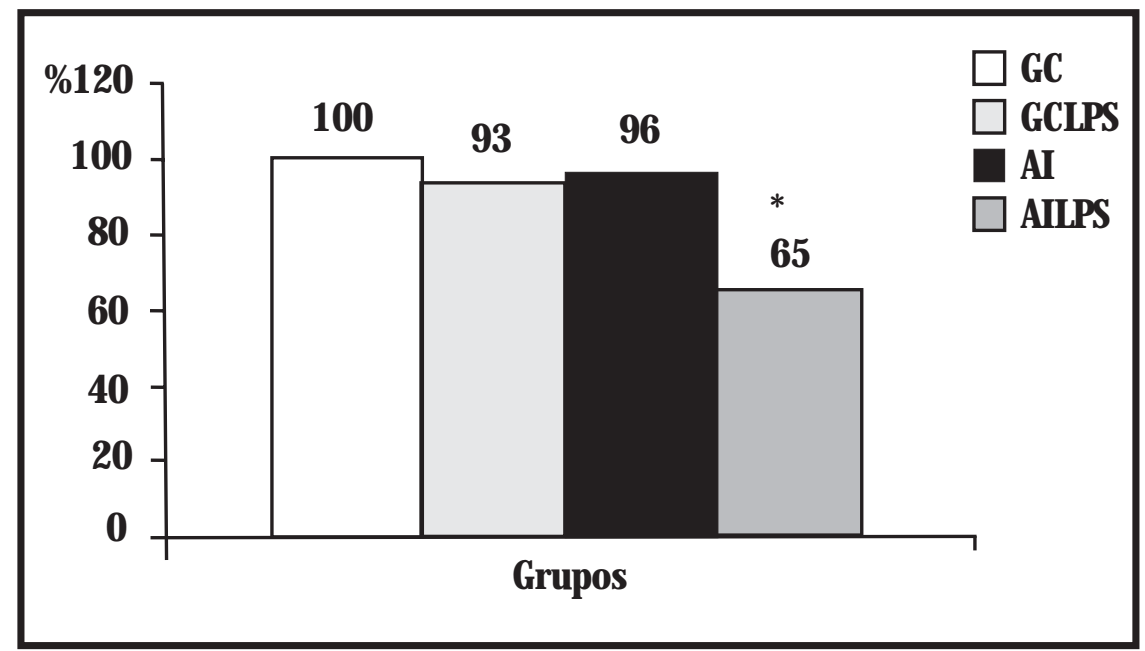

Grupo controle com células sem tratamento com LPS ou tratadas com LPS, respectivamente: GC e GCLPS. Grupo auto-implante com células não tratadas com LPS ou tratadas com LPS, respectivamente: AI e AILPS. As absorvâncias foram transformadas e representados pelas médias \pm desvios padrão do percentual de viabilidade celular.

*As diferenças determinadas pelo teste de ANOVA e teste de Tukey-Kramer, com p<0,05.

Figura 2 - Percentual de viabilidade celular dos diferentes grupos. 


\section{DISCUSSÃ0}

A SFPE é causada na maioria dos casos por pneumococos, cujos polissacarídeos da cápsula são considerados antígenos do tipo 2 células T independentes. É conhecido que a iniciação da resposta imune depende da presença de tecido esplênico, em particular do compartimento funcional marginal de células B. Assim sendo, a memória IgM das células B requerem tecido esplênico para sua geração e ou sobrevida, e são responsáveis pela proteção contra bactérias encapsuladas ${ }^{14}$.

Muito embora 0 auto-implante de tecido esplênico esteja sendo realizado numa tentativa de restaurar a função imune normal do baço, ainda é bastante controversa na literatura mundial atual a capacidade deste tecido auto-transplantado em iniciar uma reação primária humoral aos antígenos TI-2, e assim prevenir contra SFPE.

No presente estudo, os pacientes que constituíram o grupo dos pacientes esplenectomizados e que receberam auto-implante esplênico foram também submetidos a profilaxia contra SFPE, e a incidência desta foi nula. Estudos anteriores demonstram que a regeneração do tecido esplênico auto-implantado se faz melhor em indivíduos jovens do que mais velhos ${ }^{11}$. Portanto, a faixa etária incluída no presente estudo parece reproduzir a época de melhor regeneração do tecido auto-implantado permitindo a análise das funções imunes de forma mais fidedigna.

A esplenectomia associada ao auto-implante de tecido esplênico no grande omento, também é citada em trabalhos anteriores sugerindo ser este local de implante escolhido o mais apropriado, em função da rica vascularização e da abundância de células inflamatórias, fatores de crescimento e citocinas, e pelo fato do sangue venoso desta estrutura drenar para a veia porta, assim como 0 sangue proveniente do baço. A confecção da bolsa omental acrescenta ainda, a vantagem de colocar as duas faces do baço em contato com 0 folheto omental ${ }^{45}$.

Com relação à massa de tecido esplênico implantado, no presente estudo, implantou-se fragmentos de $2 \times 2 \mathrm{~cm}$ do pólo superior do baço com massa esplênica total de aproximadamente $100 \mathrm{~g}$, próximo ao peso normal do baço para o grupo etário incluído no estudo. Outros autores, porém, advogam que não há uma correlação direta entre 0 peso da massa esplênica implantada e a massa regenerada, não havendo também diferença na quantidade de tecido regenerado nem no fluxo sangüíneo por grama de tecido esplênico, quando 0 baço é implantado parcialmente ( $50 \%$ ) ou por inteiro. 0 fluxo sanguíneo da esplenose, para estes mesmos autores, situa-se em torno de $15 \%$ dos valores controle ${ }^{23}$.

Além da quantidade adequada de tecido esplênico implantado 0 estudo de fagócitos é importante no sentido de que com a retirada do baço, quantidade enorme destas células são retiradas do hospedeiro e, portanto a resposta às bactérias é prejudicada ${ }^{8}$. No caso do auto-implante, estes irão manter uma certa quantidade destas células. Os fagócitos mononucleares exibem mudanças físicas e bioquímicas, incluindo aumento do tamanho, conteúdo protéico, atividade de enzimas lisossômicas, fagocitose, produção de ânion superóxido e atividade tumoricida.
Afagocitose desenvolvida por estas células é 0 início do conjunto das atividades biológicas de toda a resposta imunológica, que é constituída por várias etapas tais como: aderência ao substrato, quimiotaxia, ingestão de partículas inertes e produção de superóxid0 ${ }^{5}$.

Na presente análise, a taxa de fagocitose estudada foi semelhante entre os dois grupos, controle e auto-implantados, sugerindo que este parâmetro funcional se manteve dentro dos padrões de normalidade como ocorreria com indivíduos com 0 baço original. Este dado vem a concordar com vários autores que avaliaram a capacidade fagocítica dos pacientes autoimplantados. Em 1990, Shokouh-Amiri e cols ${ }^{27}$ estudaram experimentalmente 0 papel da esplenectomia com autoimplante esplênico em relação a função fagocitária no sangue periférico, e observaram que a esplenectomia diminuía a capacidade fagocítica e que a mesma se normalizava após 0 auto-implante esplênico ${ }^{27}$.

Ainda apresentando resultados concordantes com 0 presente estudo, em 1994, Heuneking e cols ${ }^{11}$ analisaram a maior incidência de regeneração do tecido esplênico em seres humanos, através de estudo clínico retrospectivo. Os autores analisaram 21 pacientes entre 10 e 17 anos que receberam autoimplante esplênico após esplenectomia, comparando-os com indivíduos apenas esplenectomizados da mesma faixa etária. E analisaram a taxa de fagocitose para pneumococo in vitro. Os resultados demonstraram a plena eficácia do tecido esplênico auto-implantado ${ }^{11}$.

0 papel do baço autotransplantado na proteção contra bactérias encapsuladas ainda é melhor estudado do que em relação as bactérias não encapsuladas. 0 ensaio realizado por Thalamer e cols ${ }^{31}$, em 1986, trata-se do clearance de bactérias Gram-negativas não encapsuladas e que os autores constataram uma grave disfunção em autotransplantados quando comparados com baços normais, exercendo apenas $2 \%$ da atividade microbicida do grupo controle. A razão deste feito, especulada pelos autores parece ser 0 tamanho limitado da massa transplantada e/ou ainda, redução de funções imunes específicas nos pacientes esplenectomizados. A vacinação contra E. coli aumentou a eficiência da atividade macrofágica de ambos os grupos estudados ${ }^{31}$.

Entretanto, contrariando os achados do presente estudo, outros autores discordam de que 0 auto-implante esplênico seria capaz de preservar a capacidade fagocítica como nos indivíduos normais. Smith \& De Young ${ }^{28}$, em 2003, realizaram experimento com ratos seis meses após terem sido submetidos à esplenectomia e auto-implante esplênico. Os autores procederam a investigação da capacidade de fagocitose de células no tecido esplênico regenerado, in vitro, sem influência do clearance hepático. Observaram que o tecido auto-implantado contém menos fagócitos que o tecido esplênico normal e esses fagócitos fagocitam menos por célula, concluindo que o tecido esplênico autotransplantado não restauraria a capacidade fagocítica perdida após esplenectomia não eliminando assim 0 risco de $\mathrm{SFPE}^{28}$. Ainda utilizando o mesmo modelo animal de ratos, os autores estudaram a eficácia do tecido implantado em fagocitar bactérias. Após 6 meses de esplenectomia e auto-implante 
esplênico, os ratos, divididos em grupos controle e autoimplantados, foram sacrificados e uma suspensão de células esplênicas foram expostas a $S$. aureus. Observaram que as células do tecido esplênico auto-implantado fagocitaram menos bactérias ao longo de 60 minutos. Constataram ainda, que 0 aumento da fagocitose seria feito de forma mais lenta em relação ao grupo controle e apenas atingiria sua atividade plena cerca de 60 minutos além do tempo que levaria 0 tecido esplênico normal para atingir o platô de sua capacidade fagocitária máxima.

Os autores concluíram, portanto, que o tecido autoimplantado em modelo animal contém menos fagócitos e estes parecem apresentar menor índice de fagocitose por célula ${ }^{29}$.

Tem sido admitido limitações ao remanescente esplênico em cumprir seu papel na resposta imunitária em seus vários níveis ${ }^{2829}$. Porém, existem ensaios cujos autores concluíram que 0 tecido esplênico auto-implantado pode contribuir sinérgica ou isoladamente, em fases diferentes da resposta imune, para que o monócito tenha uma atividade microbicida próxima ao normal através das funções imunes que continuam se processando no tecido auto-implantado ${ }^{315}$.

Tem sido demonstrado que a aderência dos macrófagos de ratos esplenectomizados é diminuída, contudo 0 autoimplante esplênico restauraria esta atividade funcional. Entretanto, Brandt e cols ${ }^{5}$ constataram que se comparando pacientes auto-implantados e esplenectomizados sem autoimplante, 0 índice de aderência de monócitos foi semelhante ao grupo de indivíduos sadios. Sendo possível inferir que a esplenectomia seguida ou não de auto-implante esplênico não interfere nesta propriedade das células monocíticas ${ }^{5}$.

Outro aspecto da imunidade em pacientes autoimplantados avaliados no presente estudo foi a viabilidade celular de monócitos do sangue periférico. Para isto, utilizouse 0 ensaio do MTT.

Na literatura, não há relatos de estudos de viabilidade celular de monócitos em pacientes esplenectomizados com auto-implante de tecido esplênico. Em nosso estudo, avaliou-se a viabilidade celular de monócitos do sangue periférico em pacientes autoimplantados com e sem estímulo do LPS bem como a viabilidade de monócitos do sangue de indivíduos normais com e sem estímulo do LPS. Constatou-se que, quando comparados os pacientes autoimplantados cujas células não foram expostas ao LPS com indivíduos sadios também sem exposição de suas células ao LPS não houve diferença nestes grupos. No entanto, diferença houve quando se comparou as células dos pacientes auto-implantados com as do grupo controle expostas à estimulação prolongada com o LPS, pelo período de 22 horas.

Verificou-se que, após este tempo de estímulo, no grupo controle houve uma mortalidade das células de $7 \%$ apenas, enquanto no grupo de auto-implantados, a mortalidade das células foi de 31\%. Tal diferença é significante e sugere que fagócitos mononucleares dos pacientes auto-implantados podem ter menor viabilidade frente a um estímulo nocivo e de longa duração, mas certamente terá uma maior viabilidade das células do que aqueles pacientes apenas esplenectomizados sem nenhum tecido esplênico auto-implantado.
Em relação à viabilidade celular de monócitos do sangue periférico, estimulados com LPS, percebe-se que os pacientes submetidos à esplenectomia e auto-implante quando estimulados pelo LPS por 22 horas apresentaram uma viabilidade celular menor que os pacientes do grupo controle sob o mesmo estímulo. Pode-se inferir, portanto, que a mortalidade de monócitos dos pacientes que receberam autoimplante frente a um estímulo nocivo e prolongado é maior do que em indivíduos normais e que, portanto, a resposta imune assumida pelo tecido esplênico auto-implantado pode não ser assumida em sua forma plena e desta forma 0 autoimplante, isoladamente, pode não ser capaz de prevenir contra SFPE sem medidas clínicas profiláticas adicionais.

Corroborando com o presente estudo, em estudo anterior, Brandt e cols $s^{4}$ analisando a atividade microbicida de monócitos tratados com acetato miristato de forbol (PMA) ou com PMA e tuftsina, avaliaram a liberação do radical superóxido, em pacientes esplenectomizados com auto-implante esplênico e observaram que nestes pacientes a atividade microbicida foi apenas satisfatória na fase inicial. As células poderiam não ter capacidade de produzir superóxido em quantidade crescente e suficiente para uma resposta do hospedeiro completa, de destruição dos microorganismos. Os mesmos autores avaliaram em outro estudo, a liberação de TNF- $\alpha$ por monócitos do sangue periférico cultivados, in vitro, estimulados com PMA e observaram que os resultados não diferiram entre os grupos controle, auto-implantados e esplenectomizados sem autoimplante ${ }^{5}$.

Finalmente, no presente estudo, pode-se supor que 0 tecido esplênico auto-implantado pode auxiliar na prevenção contra SFPE, assegurando funções mono-macrofágicas antes exercidas pelo baço original, como a capacidade de fagocitar. Todavia, a viabilidade celular dos monócitos nos pacientes auto-implantados, frente a estímulo nocivo e prolongado encontra-se deficiente. Isso pode sugerir que monócitos de pacientes esplenectomizados com auto-implante são mais sensíveis frente a um estímulo, por exemplo, o LPS que é uma endotoxina liberada no crescimento ou morte de enterobactérias. 0 estudo apresentado tenta fundamentar a hipótese de que 0 auto-implante esplênico pode influenciar de forma positiva em algumas funções dos fagócitos mononucleares.

Os resultados obtidos comparando-se indivíduos saudáveis com pacientes esquistossomóticos jovens submetidos à esplenectomia, ligadura de veia gástrica esquerda e autoimplante esplênico no grande omento permitem concluir que: Os monócitos no sangue periférico de pacientes esplenectomizados com auto-implante esplênico têm atividade fagocítica semelhante ao de pacientes sadios; Os fagócitos mononucleares dos pacientes auto-implantados possuem menor viabilidade frente à estimulação nociva e prolongada.

Assim, considera-se a possibilidade da existência de graduações de disfunção no sistema retículo endotelial, destes pacientes. 


\section{REFERÊNCIAS BIBLIOGRÁFICAS}

1. Alvarez FE, Greco RS. Regeneration of the spleen after ectopic implantation and partial splenectomy. Archives of Surgery 115:772-775, 1980.

2. Amaral RS, Porto MAS. Evolução e situação atual do controle da esquistossomose no Brasil. Revista da Sociedade Brasileira de Medicina Tropical 27:73-90, 1994.

3. Bergmann L, Bttcher W, Seufert RM, Mitrou PS. Quantitative and functional restorations and alterations of perifheral lymphocytes in patients with autologous spleen implantation. Archives of Orthopaedic and Trauma Surgery 109:102-105, 1990.

4. Brandt CT, Araújo LB, Castro CMMB. Autotransplantation of spleen tissue in children with mansonic schistosomiasis who underwent splonectomy: evaluation of splenic residual functions. Acta Cirúrgica Brasileira 13:212216, 1998.

5. Brandt CT, Leite CRC, Castro RM, Castro CMM. Aderência e atividade microbicida em portadores de esquistossomose mansonica na forma de cirurgia. Acta Cirúrgica Brasileira 18:1-23, 2003.

6. Brandt CT, Maciel DT, Caneca OAF, Castro CMMB, Araújo LB. Autotransplant of spleen tissue in children with schistosomiasis: evaluation of splenic function after splenosis. Memórias do Instituto Oswaldo Cruz 96:117-122, 2001.

7. Brandt CT, Oliveira BS, Nogueira JBM, Neves JR, Lopes TL. Esquistosomose hepatoesplênica em crianças: avaliação funcional e morfológica após esplenectomia e auto-implante esplênico. Revista do Colégio Brasileiro de Cirurgiões 25:399-402, 1998.

8. Davidson RN, Wall RA. Prevention and management of infections in patients without spleen. Clinical Microbiology and Infection 7:657-660, 2001.

9. Guerra LCM, Neto JE, Miranda PJC, Silveira MJC, Brandt CT, Kelner S. Variações dos valores séricos das imunoglobulinas IgG, IgA e IgM, C3 e C4 após esplenectomia em esquistossomóticos hepatoesplênicos. Acta Cirúrgica Brasileira 6:123-127, 1991.

10. Harding B, Kenny F, Given F, Murphy B, Lavelle S. Autotransplantation of splenic tissue after splenectomy in rats offers partial protection against intravenous pneumococal challenge. European Surgical Research 19:135-139, 1987.

11. Heuneking K, Muller C, Franke F, Becker H, Schwemmle K. Follow-up of Heterotopic autotransplantation of splenic tissue after traumatic splenic rupture in childhood. Chirurgic 65:457-468, 1994.

12. Katz N, Peixoto SV. Análise crítica da estimativa do número de portadores de Esquistossomose mansoni no Brasil. Revista da Sociedade Brasileira de Medicina Tropical 33:303-308, 2000.

13. Koren A, Haasz R, Tiatler A, Katazumi E. Serum immunoglobulin levels in children after splenectomy - A prospective study. American Journal of Diseases Children 138:53-55, 1984.

14. Kruetzmann S, Rosado MM, Weber H, Germing U, Tournilhac, Hans-Hartmut P, Berner R, Peters A, Boehm T, Plebani A, Quinti I, Carsetti A. Human immunoglobulin M memory B cells controlling Streptococcus peneumonie infections are generated in spleen. Journal of Experimental Medicine 197:939-945, 2003.

15. Leemans R, Harms G. Spleen autotransplantation provides restoration of functional splenic lymphoid compartments and improves the humoral immune response to pneumococcal polysacharide vaccine. Clinical Experimental Immunology 117:596-604, 1999 .
16. Ludke FE, Mack. Splenic function after splenectomy for trauma. Role of autotransplantation and splenosis. Acta Chemica Scandinavica 155:533539,1989 .

17. Malangoli M, Evers BM, Peyton JC, Wellhausen SR. Reticuloendothelial cleareance and splenic mononuclear cell populations after resection and autotransplantation. American Journal of Surgery 155:302, 1988.

18. Moore GE, Stevens RE, Moore EE, Aragon GE. Failure of splenic implants to protect against fatal postsplenectomy infection. American Journal of Surgery 146:413-414, 1983.

19. Nielsen J, Buskjaer L, Lamm L. Complement studies in splenectomized patients. Scandinavian Journal of Haematology 30:194-200, 1983.

20. Pabst R, Kamram D. Autotransplantation of splenic tissue Jounal of Pediatric Surgery 21:120-124,1986

21. Patel JM, Williams JS, Naiss JO, Hinshaw JR. Protection against pneumococcal sepsis in splenectomized rats by implantation of splenic tissue into an omental pouch. Surgery 91:683-691, 1982.

22. Patel JM, Williams JS, Shijel B, Hinshaw JR. Preservation of splenic function by autotransplantation of traumatized spleen in man. Surgery 90:683-688, 1981.

23. Petroianu A, Barbosa AJA. Quantitative studies on macrophage phagocytosis in whole spleen and in remnant of subtotal splenectomy. Medical Science Research 19:373-375, 1991

24. Resende V, Petroianu A. Estudo funcional tardio do auto-implante esplênico após trauma complexo do baço humano. Revista do Colégio Brasileiro de Cirurgiões 28:165-170, 2001

25. Rodrigues AZ, Nigro AJT, Paiva ER, Tavares NM. Estudo comparativo da viabilidade de fragmento de tecido esplênico autólogo implantado no omento maior ou na tela subcutânea de ratas. Acta Cirúrgica Brasileira 6:64-67, 1991.

26. Salem SA, Makeled MK. Immunological changes in splenectomized versus non splenectomized schistosomal hepatosplenic cases. Journal of the Egyptian Society of Parasitology 17:785-796, 1987.

27. Shokouh-Amiri MH, Kharazami A, Rahimi-Saber S, Hansen CP, Jensen SL. Phagocyte function after splenic autotransplantation. Archives of Surgery 125:595-597, 1990.

28. Smith E, J De Young N. Decreased phagocytic capacity of autotransplantes splenic tissue. ANZ Journal of Surgery 73: 894-896, 2003.

29. Smith E, J De Young N. Decreased phagocytic capacity of autotransplantes splenic tissue. Journal of Pediatrics Surgery 39:1148, 2004.

30. Sulivan JL, Ochs HD, Schiffman G. Immune response after splenectomy. Lancet 1:178-181, 1978.

31. Thalhamer J, Pimpl W. The role of the spleen and splenic autotransplants in clearing experimental bacteremia caused by the gram-negative bacterium Escherichia coli. Research in Experimental Medicine (Berl) 186: 229238, 1986.

32. Timens W, Leemans R. Splenic autotransplantation and the immune system. Annals of Surgery 215:256-260, 1991.

33. Vega A, Howell C, Krasna l, Campos J, Heyamn S, Ziegler M, Koop E. Splenic autotransplantation: optimal functional factors. Journal of Pediatrics Surgery 16:898-904, 1981.

34. Zoli G. Splenic autotransplantation after splenectomy tuftisin activity correlates with residual splenic function. British Journal of Surgery 81:716-718, 1994. 